\title{
Optics and communication technology major of physics undergraduate degree at King Mongkut's Institute of Technology Ladkrabang
}

Prathan Buranasiri

Prathan Buranasiri, "Optics and communication technology major of physics undergraduate degree at King Mongkut's Institute of Technology Ladkrabang," Proc. SPIE 9188, Optics Education and Outreach III, 91880A (15 September 2014); doi: 10.1117/12.2062503

SPIE Event: SPIE Optical Engineering + Applications, 2014, San Diego, California, United States 


\title{
Optics and Communication Technology Major of Physics Undergraduate Degree at King Mongkut's Institute of Technology Ladkrabang
}

\author{
Prathan Buranasiri* \\ King Mongkut's Institute of Technology Ladkrabang, Physics Department, Faculty of Science, Lat \\ Krabang, Bangkok 10520, Thailand
}

\begin{abstract}
A physics undergraduate degree major in optics and communication technology has been offered at King Mongkut's Institute of Technology Ladkrabang (KMITL), Bangkok, Thailand. There are nine required three credit hour courses including two laboratory courses plus a number of selections in optics and communication based technology courses. For independent thinking and industrial working skills, nine credit hours of research project, practical training or overseas studies are included for selection in the final semester. Students are encouraged to participate in international conferences and professional organizations. Recently the program, with support from SPIE and OSA, has organized its first international conference on photonic solutions 2013 (ICPS 2013).
\end{abstract}

Keywords: Optics undergraduate education, curriculum, practical training, overseas study, international conference, undergraduate project

\section{INTRODUCTION}

Currently, optics and photonics are at the heart of new technologies in telecommunications, medicine, nanotechnology, and manufacturing etc. Optics and photonics provide efficient approaches to solutions of many problems of science and technology. In Thailand, fiber-optic communication network systems have been deployed around the country by both government agencies and private companies due to the need of internet users. A number of modern manufacturers have been using optical technology to assist in areas such as laser processing of engineering materials, sensors, and laser scanning. In medical science, optical and photonic techniques have been utilized in many applications such as high precision surgery, laser thermal effects of tissues, using fiber optics to monitor human organs. In nanotechnology, photonic approaches can help scientists and engineers to fabricate, design and explore a number of modern devices such as light emitting diodes, semiconductor lasers, and solar cells.

Although some optics related courses have already been offered in different major science and engineering areas of many universities in Thailand, there needs to be an increased focus on optics and photonics education in our country. An optics and communication major has been established as one of four majors in our physics department at the Faculty of Science, KMITL, Bangkok, Thailand four year ago. To the best of our knowledge, it is the first and only optics based curriculum in Thailand. The purpose is to train undergraduate students who, after graduation, can use their knowledge in the optics and photonics industry and/or pursue graduate education in universities both in Thailand and abroad. In addition, collaborations in optics research and education with the other universities and private companies both aboard and in Thailand have been developed. Some famous researchers have been invited to give presentations for our students both directly in the physics department and in a recent conference organized by us. In 2013, the physics department at KMITL, with support from the National Electronics and Computer Technology Center (NECTEC), SPIE and OSA, has kick-started the first optics conference, named the International Conference on Photonic solutions (ICPS 2013). ICPS has been planned for every year or every other year and organized by different hosts in the future. Recently two groups of optics and communication students have graduated from our program in 2013 and 2014. A number of optics and communication program (OCP) students from these groups have been working in optics related research and development in both private sections and in different graduate schools.

*kbpratha@kmitl.ac.th; phone 6695 517-8237.

Optics Education and Outreach III, edited by G. Groot Gregory, Proc. of SPIE Vol. 9188,

91880A @ 2014 SPIE $\cdot$ CCC code: $0277-786 X / 14 / \$ 18 \cdot$ doi: $10.1117 / 12.2062503$ 


\section{THE OPTICS AND COMMUNICATION MAJOR AT KMITL}

The physics department of KMITL, formerly the applied physics department since its curriculum concentrated on applied physics courses, was founded in the faculty of industrial education and science to support the electronics industry in Thailand. In 1988, the faculty of science was separated from industrial education. In order to support the electronics industry, the curriculum of applied physics department initially concentrated on only applications of solid state physics, called solid state electronics, although it has also offered a number of applied physics courses in other areas such as optics, renewable energy, environmental physics, and instrumentation. To cater to the need of instrumentation scientists in the Thai manufacturing industry, the industry instrumentation was added to the physics curriculum. In 2009, the new applied physics curriculum has been rewritten and then separated to four majors, i.e. solid state electronics, industry instrumentation physics, optics and communication, renewable energy. The core of the old curriculum has been still retained in the new curriculum. Some elective courses from the old curriculum have been grouped together, and some new courses have been created for each major. In this paper, only optics and communication curriculum will be discussed in detail.

In the first two years, students who have studied in all majors are required to take the same fundamental courses such as calculus, biology, and chemistry, and fundamental physics classes such as electromagnetics, classical mechanics, and thermodynamics. In their third year, students will be asked to choose their own major; however, students in all majors are required to take the same basic engineering classes such as digital electronics, and microcontroller based courses. In our opinion, the skill from these engineering classes would be needed by the students in their research and career.

In any major, there are eight to ten different courses related to the major. Two three-hour laboratory courses, which consist of experiments in geometrical and physical optics, generation and properties of lasers, Fourier optics, fiber optics, and spectroscopy have been incorporated as required courses for better understanding of the corresponding lecture courses and for enhancing student research technical skills. Some more modern optics and photonics experiments have been created and added to these courses every year. One free major physics course has been added to the curriculum which can be chosen by the student in his/her own area of interest. For improving independent thinking of the students, six credit hour research project courses have been included in the curriculum. In order to get real life research problems and more research opportunities, the students also have been allowed to conduct their research projects with private companies, industries, or research institutes under the advice from our faculty members. Table 1 summarizes the applied physics curriculum with a major in optics and communication ${ }^{1}$. Based on our experience of teaching students in this new curriculum for two years, the curriculum was tweaked to better fit the students' schedule and suit their background. Normally, the curriculum is scheduled for major improvements every four years.

\section{THREE RESEARCH OPTIONS FOR OCP SENIOR STUDENTS}

\subsection{Special Project}

Due to the convenience and a number of research choices in the department, Special Projects (see Table 1) is the main option that almost all of the students have chosen to work on for their final year study to get the degree. However, the program encourages the OCP students to select the other two options (co-operation education and oversea training), so they can participate in the real world work during their study time. In the department, students can either choose the project that the faculty prepares for them as a senior project, or they may create the project from their own ideas. The OCP students have been allowed to work on a project under the supervision from a graduate student. Since the program emphasizes the importance of real-world experience, students also have been encouraged to present their own research projects in an international conference. Some examples of senior projects in optics so far are digital holography, photorefractive optics, low cost optical tweezers, LIDAR, computational optics, optical communication, optical interferometer, etc. In low cost optical tweezers project ${ }^{2}$, a group of students designed an optical tweezer system using double coil driving stepping motor for controlling sample stage instead of using a high cost stage using piezoelectric transducer (PZT). This work was presented by one of the students, who had worked in this project, at ICPS 2013 and also was published in a SPIE Proceedings ${ }^{2}$. In the photorefractive optics project, a student has prepared and characterized photorefractive polymers of carbon allotropes ${ }^{3}$. His work was presented in a poster session of Siam Physics Congress $2014^{3}$. A number of students also work on some research projects by collaborating with experts in other universities or government research agencies. An example of research collaboration with another university is the investigation of structural and optical properties of InGaPN grown on GaAs (001) by metal organic vapor phase epitaxy (MOVPE) ${ }^{4}$ with 
Dr.Sakuntam Sanorpim of Physics department, Chulalongkorn University. In this project, one of our faculties was his research advisor and Dr Sanorpim was his co-advisor.

Table 1. OCP Curriculum, Physics Department, Faculty of science, KMITL

First year

\begin{tabular}{|l|c|l|c|}
\hline Semester one & Credits & Semester two & Credits \\
\hline Calculus I & 3 & Calculus II & 3 \\
General Biology & 3 & General Chemistry & 3 \\
General Biology Laboratory & 1 & General Chemistry Laboratory & 1 \\
Fundamental Physics I & 3 & Fundamental Physics II & 3 \\
Fundamental Physics Laboratory I & 1 & Fundamental Physics Laboratory II & 1 \\
Engineering Workshop & 1 & Engineering Drawing and Computer Aided Design & 1 \\
Elective Topics in Language & 3 & Elective Topics in Language & 3 \\
Elective Topics in Science and Mathematics & 3 & Elective Topics in Humanity & 3 \\
Elective Topics in Social Science & 3 & & \\
\hline
\end{tabular}

Second year

\begin{tabular}{|l|c|l|c|}
\hline Semester one & Credits & Semester two & Credits \\
\hline Mathematical Physics & 3 & Numerical Analysis in Physics & 3 \\
Fundamental Programming & 3 & Thermal and Statistical Physics & 3 \\
Electric Circuit Theory and Analysis & 3 & Quantum Mechanics & 3 \\
Electromagnetic Fields & 3 & Wave and Vibration & 3 \\
Mechanics & 3 & Electronics & 3 \\
Intermediate Physics Laboratory I & 1 & Intermediate Physics Laboratory & 1 \\
Elective Topics in Language & 3 & Elective Topics in Language & 3 \\
& & Elective Topics in Social Science & 3 \\
\hline
\end{tabular}

Third year

\begin{tabular}{|l|c|l|c|}
\hline Semester one & Credits & Semester two & Credits \\
\hline Solid State Physics & 3 & Digital Electronic Laboratory & 2 \\
Electronic Laboratory & 2 & Microcomputer-Based Experimental Laboratory & 1 \\
Digital Electronics & 3 & Communication System Laboratory & 3 \\
Microcontroller and Programming & 3 & Laser Physics & 3 \\
Material Science and Engineering & 3 & Optical Communication Network & 3 \\
Geometrical and Physical Optics & 3 & Free Major Courses & 3 \\
Optical and Communication Laboratory 1 & 1 & Elective Topic in Humanity & 3 \\
Elective Topics in Science and Mathematics & 3 & Free Elective Courses & 3 \\
\cline { 1 - 2 } Semester three & Credits & & \\
\cline { 1 - 2 } Training & 0 &
\end{tabular}

\begin{tabular}{|l|c|l|l|}
\hline \multicolumn{2}{l}{ Fourth year } & Credits \\
\hline Semester one & Credits & Semester two & \\
\hline Seminar & 1 & Special Projects & \\
Optical Devices and Instruments & 3 & or & 6 \\
Photonics & 3 & Co-Operative Education & \\
Optical and Communication Laboratory 2 & 3 & or & \\
Free Major Course & 3 & Overseas Training & \\
Free Elective Course & 3 & & \\
\hline
\end{tabular}

\subsection{Co-Op Education}

Due to the importance of working experience, co-op education has been added to be one of selection for complete their study. We are in the process of establishing MOU programs with industries, other universities, and government agencies. So far, no student has done real co-op education; however, a number of OCP students have been working on 
their research projects with private industries, other universities, and government agencies under a faculty in the department as their project advisors, such as the MOVPE project mentioned above. A group of students worked on ahybrid fiber-optic co-axial network research project in a private telecommunication company ${ }^{5}$. In this project, students learnt how fiber optic communication networks work in real life. In the future, we hope that our students will go out to do co-op education in a real working atmosphere without having our faculty in the department support any part of their projects.

\subsection{Oversea-training}

The first OCP student has completed overseas training in soft matter and biophotonics laboratory with Prof. H. Daniel Ou-Yang of the physics department at Lehigh University in the United States for six months. She studied mechanical and physical properties of cells by using optical tweezers for her research topics ${ }^{6}$. Prof. Ou-Yang kindly allowed one of our graduate students to work on a research project in his laboratory. Prof. Ou-Yang has visited us and also given presentation in KMITL when he visited Thailand. As in the case of co-op education, we are in the process of establishing MOU programs with some international research sections and universities.

\section{ICPS 2013}

In year 2013, the program, on behalf of the physics department, Faculty of Science, KMITL, organized the International Conference on Photonic solutions 2013 (ICPS 2013). The purpose of this was to increase general awareness of optics and photonics, and provide the opportunity to our OCP students or any researcher interested in optics and photonics to participate and exchange their ideas with fellow national and international professionals in the photonics area. Dr. Prathan Buranasiri of the physics department KMITL and Dr. Sarun Sumriddetchkajorn of NECTEC were chairs of the conference. A number of nationally and internationally renowned optics and photonics scientists and engineers were part of the conference committee.

The first conference venue was at the Royal Cliff Beach hotel in Pattaya city, which has a very famous beach. In this conference, we were grateful to have three plenary lectures who are leading photonics scientists in their fields: Prof. James C. Wyant of University of Arizona, Prof. Toyohiko Yatagai of Utsonumiya University, and Prof. Hiroshi Yoshikawa of Nihon University. There were 46 participant papers which included one plenary paper, and six invited papers. All papers in the conference have been also published in the Proceeding of SPIE issue $8883^{7}$. After the conference, some invited speakers, Prof. Joseph W Haus and Prof. Partha Banerjee of Electro-Optics program University of Dayton, Prof. H. Daniel Ou-Yang of Physics department, Lehigh University, and Prof. Kyu Yoshimori of Iwate University were invited to visit us at KMITL and give presentations for our faculty and students. Prof. Yoshimori and we are in the process of establishing an MOU for double $\mathrm{PhD}$ degrees between Iwate University and KMITL as well. The first ICPS has been a successful endeavor to popularize optics and photonics, and we welcome other universities or industries to organize ICPS in the future.

\section{CONCLUSION}

An optics and communication major curriculum is offered in the physics department, KMITL Thailand. It is the first optics and photonics curriculum in the country. The curriculum is focused on applied classes in both science and technology, so that the students acquire the skill for working in research and industrial environments. Advanced laboratory based courses have been included in the program to develop student experimental skills and their real understanding in class coursework. The OCP students have been encouraged to participate with optics professionals. Three choices for OCP students for improving working experience are special projects, co-op education, and overseas training. Some renowned optics professional have been invited to give talks for faculty and students in the department. Recently, the department organized a conference name ICPS 2013 for promoting the optics research, business, and industry in Thailand. 


\section{REFERENCES}

[1] Physics Department, "Student Handbook," Faculty of Science, King Mongkut's Institute of Technology Ladkrabang (2011).

[2] Laowattanatham, N. Cheamanunkul, N. Plaipichit, S. Buranasiri, P. and Nuansri, R., "Low cost optical tweezers systems using double coil driving stepping motor to controlling sample stage," Proc. SPIE 8883, 8883U-1(2013).

[3] Bamrungthai, T., "Preparation and synthesis of photorefractive polymer of carbon allotropes as photo sensitizers," Undergraduate Special Project, KMITL (2014).

[4] Kengkaroonkrit, S., "Investigation of structural and optical properties of InGaPN grown on GaAx (001)by metal organic vapor phase epitaxy (MOVPE)," Undergraduate Special Project, KMITL (2014).

[5] Phadungpak, P. and Thummasut, O., "A study of coaxial cable network designing in the hybrid fiber coax Network (HFC NETWORK),” Undergraduate Special Project, KMITL (2013).

[6] Thong-on, T., "The study of mechanical and physical properties of HE-LA cells by using optical tweezers," Undergraduate Overseas Training Project, KMITL (2014).

[7] Buranasiri, P. and Sumriddetchkajorn, S., "ICPS 2013: International Conference on Photonics Solutions," Proc SPIE 8883 (2013). 